\title{
Morphology Controlled Electrolytical Method of Preparation of Copper Nanoparticles with Various Capping Agents
}

\author{
Govindaraj Usha, Jamuna Kannan, Narayanan Selvapalam, Ramesh Prakash, \\ Lakshminarayanan Piramuthu
}

\begin{abstract}
Morphology controlled copper nanoparticles synthesis has been carried out by electrolytical method with various capping agents such as ethanediol, DMF and milk, The results of these nanoparticles are compared with the nanoparticles that we obtained without any capping agents. The morphological variations have been monitored by the SEM. Interestingly, this electrolytical synthetic route produced many different morphologies depending on the capping agents or hydrophobic envirnoment. We believe that hydrophilic or the hydrophobic environment may the deciding factor for the determination of the morphology and our hypothesis has been examined using hydrophilic ethandiol and DMF and with hydrophobic milk. Both ethandiol and DMF produced grapes like structure, while the milk produced multifaceted crystalline structures as confirmed by the SEM. In conclusion, natural sources such as milk produced uniform sized microparticles with many interesting features..
\end{abstract}

Keywords : Electrolytical synthesis, Copper nanoparticles, capping agents, Nanowires

\section{INTRODUCTION}

Copper displayed its oxidations state in different forms. Among which copper at zero oxidation state has the best conduction property and thus the market value of this material is always next to the aluminium and silver. Copper has been utilized various purposes by the scientists that include optical, magnetic, thermal and catalytic and other purposes [1]. Copper can be retained in zero oxidation state with the help of capping agents, which prevent the copper to get oxidized to higher oxidation state. Generation of nanoparticles is a way to prevent copper to retain the oxidation state. Such nanoparticles have been employed in applications such as opto-electronics,[2] chemical sensors,[3], [4] antibacterial and antifungal activities.[5], [6]. Achieving nanometer sized

Revised Manuscript Received on December 05, 2019.

* Correspondence Author

Govindaraj Usha Center for Supramolecular Chemistry, IRC and Department of Chemistry, Kalasalingam Academy of Research and Education, Krishnankoil 626126, India. n.selvapalam@klu.ac.in

Jamuna Kannan Center for Supramolecular Chemistry, IRC and Department of Chemistry, Kalasalingam Academy of Research and Education, Krishnankoil 626126, India.n.selvapalam@klu.ac.in

Narayanan Selvapalam* Center for Supramolecular Chemistry, IRC and Department of Chemistry, Kalasalingam Academy of Research and Education, Krishnankoil 626126, India.n.selvapalam@klu.ac.in

Ramesh Prakash, Center for Supramolecular Chemistry, IRC and Department of Chemistry, Kalasalingam Academy of Research and Education, Krishnankoil 626126, India.

Lakshminarayanan Piramuthu, Center for Supramolecular Chemistry, IRC and Department of Chemistry, Kalasalingam Academy of Research and Education, Krishnankoil 626126, India. copper particles remains challenging, because the determining factor of the size control is difficult to envisage. Until now, the most popular method that has been practiced for making copper nanoparticles is chemical reduction method [7], [8]. Indeed, electrytic method has been employed for purification of metals in metallurgy; however, less work has been published on electrolytic deposition method [9] especially for copper and silver nanoparticles. Until now, sodium borohydride, citric acid and hydrazine hydrate are the mild reducing agent commonly used for the making of nanoparticles of copper with and without capping agents [10, [11]. For practical purpose copper salts are the good source to generate the nanoparticles, especially copper sulfate and copper acetate, because they are less expensive and disperse freely in water [11]. Besides, the capping agents play a major in the determination of the size of the nanoparticles and the most commonly employed capping agents are either natural extracts or the surfactants. Natural sources such as leaves extract, flower extract and polyphenolic compounds have been utilized in a larger way to obtain the nanoparticles. ${ }^{11}$ In this work, we have also extended a similar strategy to obtain the nanoparticles using various capping agents such as milk, ethandiol, DMF to understand the role of capping agent in the size determination factor. Among the various parameters of nanomaterials, size and shape play a major role in regulating the properties of the nanomaterials. Similarly, capping agent also cover the surface of the nanoparticles, which affect the physical properties of the nanoparticles. Unlike the chemical reduction method, copper nanoparticles can be conveniently prepared by applying DC voltage into the copper rods dipped in the solution of copper sulfate. There are several advantages of preparation copper nanoparticles using the electrochemical deposition methods in comparison to the chemical reduction method. Electrochemical deposition method generally produced nanoparticles in a quicker manner and it does not require any purification strategies. Furthermore, electrochemical deposition method can be utilized for the preparation of large scale synthesis with best reproducibility. Here, we have presented a new electrochemical synthetic method of preparation for the copper nanoparticles under various hydrophobic conditions to understand the shape selectivity. We have compared the morphological variations of the nanoparticles that have been prepared by the addition of ethanediol, DMF and milk. While ethanediol and DMF provide the hydrophobic environment, milk provides the opportunity to behave as a capping agent under the microenvirnment. Milk contains casein protein, which may behave differently in comparison to the

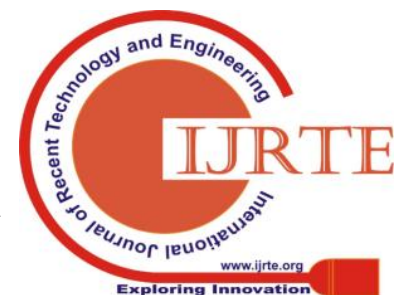


hydrophobic environment offered by the ethanediol and DMF, because proteins are larger polymers of amino acids, which can bind with copper to behave as a capping agent.

When the nanoparticles were prepared with proteins, they appear more smooth and shiny, and structurally, they are very different and morphologically it appeared close match with that of the nano-materials prepared under the hydrophobic environment; however, size parameters are unique with respect to the material that has been added during the electrolysis. Here, we have presented the work of morphological variations of copper nanoparticles that have been prepared under different hydrophobic conditions and compared with that of capping agent based nanoparticles. Under the electrochemical deposition method, we have explored the variation of hydrophobic environment with ethanediol and DMF, while milk was used as capping agent and studied their morphological variations by SEM. We have characterized the nanoparticles using SEM analysis. These nanoparticles can be potentially useful for the applications of wound healing and anti-fouling materials. Several applications are under investigation for the milk based copper nanoparticles. Other potential applications such as chemical sensors for biomaterials and toxic metals such as mercury will be explored with these nanoparticles.

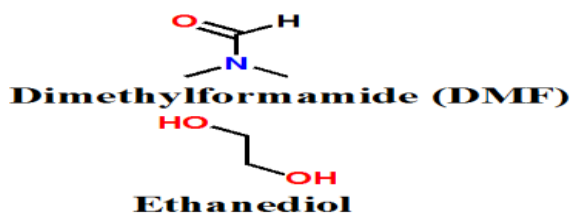

\section{EXPERIMENTAL}

\section{Preparation of Copper nanoparticles}

Copper sulfate $(5 \mathrm{~g})$ dissolved in $100 \mathrm{~mL}$ water thoroughly and DC voltage of $24 \mathrm{~V}$ and 5 A current was passed to this solution with the copper electrodes as anode as well as cathode for $3 \mathrm{~h}$ duration with stirring. Anode copper plates were having the thickness of $3 \mathrm{~mm}$ thickness and cathode was copper rods of having the thickness of $0.5 \mathrm{~cm}$. The copper nanoparticles were deposited in the rod and the force of stirrer will allow them to settle down during the reaction. The product appeared brownish and it was filtered and washed with water and acetone to get powder form.

\section{Preparation of copper nanoparticles in the presence of ethanediol}

Copper sulfate $(5 \mathrm{~g})$ and $10 \mathrm{~mL}$ of ethanediol were dissolved thoroughly in $100 \mathrm{~mL}$ water and DC voltage of $24 \mathrm{~V}$ and $5 \mathrm{~A}$ current was passed to this solution with the copper electrodes as anode as well as cathode for $3 \mathrm{~h}$ duration with stirring. The product appeared brownish and it was filtered and washed with water and acetone to get powder form.

\section{Preparation of copper nanoparticles in the presence of DMF}

Copper sulfate $(5 \mathrm{~g})$ and $10 \mathrm{~mL}$ of N,N-dimethylformamide (DMF) were dissolved thoroughly in $100 \mathrm{~mL}$ water and DC voltage of $24 \mathrm{~V}$ and $5 \mathrm{~A}$ current was passed to this solution with the copper electrodes as anode as well as cathode for $3 \mathrm{~h}$ duration with stirring. The product appeared brownish and it was filtered and washed with water and acetone to get power form.

\section{Preparation of Milk protein capped copper nanoparticles}

Copper sulfate $(5 \mathrm{~g})$ and $3 \mathrm{~mL}$ of milk were dissolved in 100 $\mathrm{mL}$ water thoroughly and DC voltage of $24 \mathrm{~V}$ and 5 A current was passed to this solution with the copper electrodes as anode as well as cathode for $3 \mathrm{~h}$ duration with stirring. The copper nanoparticles were deposited in the rod were settled down and the product appeared brownish and it was filtered and washed with water and acetone to get powder form.

\section{RESULTS AND DISCUSSION}

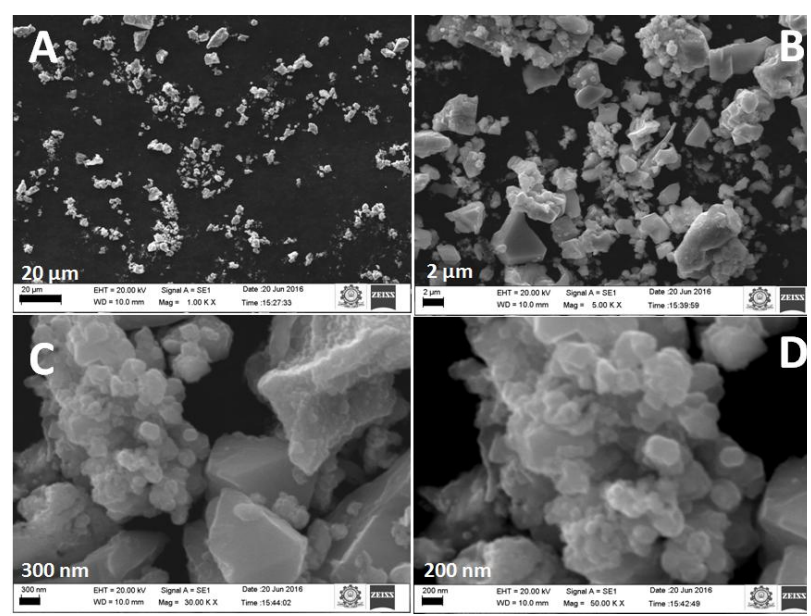

Fig. 1. SEM images of copper with no capping agent

Copper nanoparticles very often synthesized in the form of nanocrystals. 12 Among the various sources of copper salts, copper sulphate pentahydrate is an inexpensive material and thus we have used it for making the nanocrystals. Copper sulphate $(5 \mathrm{~g}, 0.2 \mathrm{M})$ was dissolved in water $100 \mathrm{~mL}$ water and dissolved by stirring. Subsequently, it formed a clear blue solution, which was loaded with the electrodes and passed the DC electricity for the duration of $3 \mathrm{~h}$. As reported by Thievashanthi, et.al., ${ }^{12}$ it showed multidimensional copper particles and the dimensions of them fall in the region of nanoparticles to micro particles, and that confirmed our process of making the electrochemical deposition method of copper nanoparticles as the particles appeared similar to that of the reported. ${ }^{12}$ As shown in Fig. 1A, the particles at low magnification were quite uniform and only at the close proximity (Fig. 1D), we could notice the multidimensional nanoparticles and a few large sized particles indicating that the method may unable to provide uniform particles, which intrigued us to investigate this electrochemical method under various conditions that include addition of various polar solvents such as ethanediol and DMF, which will create the hydrophobic environment. On the other hand, addition of biomaterials such as milk during the making of nanoparticles under electrochemical deposition method offered uniform sized shiny nanoparticles, which made this work very interesting. As an initial trial, we added $10 \mathrm{~mL}$ of ethanediol and mixed with copper sulfate solution $(5 \mathrm{~g}, 100 \mathrm{~mL}$ water $)$ and then subjected to electrochemical deposition for the period of $3 \mathrm{~h}$ with stirring. The solution became brownish 

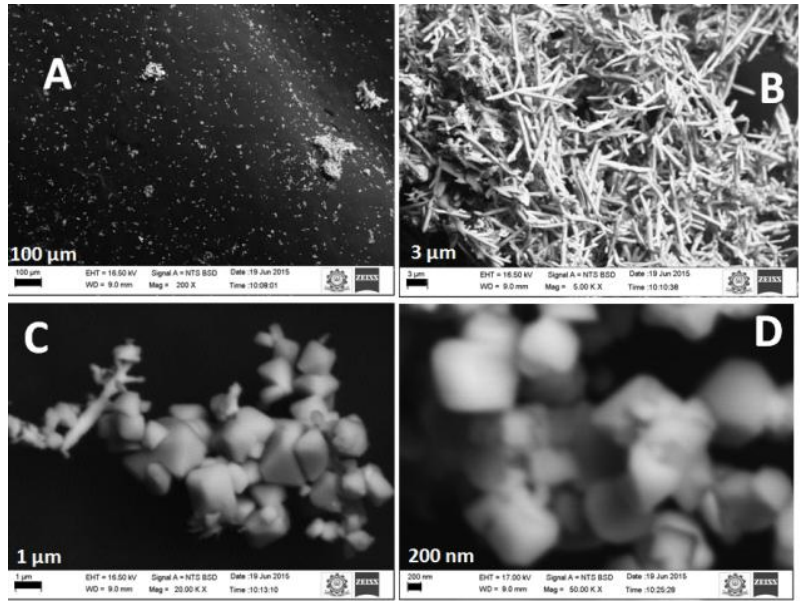

Fig. 2. SEM images of copper with ethanediol as capping agent

and settled with lots of copper particles, which were analyzed by the SEM.

Surprisingly it formed many copper rods with a few copper micro sized crystals as shown in fig.2. At low magnification, it appeared like as mini crystalline powder and at the next level magnification, it clearly indicated many rod shaped structures (fig. 2B) in the range of 200-300 nm, which is very elegant and useful for making the nano-architecture of electronic circuits at the nano level. Besides, a small fraction of sample also contains nano crystals of copper. In comparison to the water sample, ethanediol could have reduced the surface tension of the sample, which might have helped to the

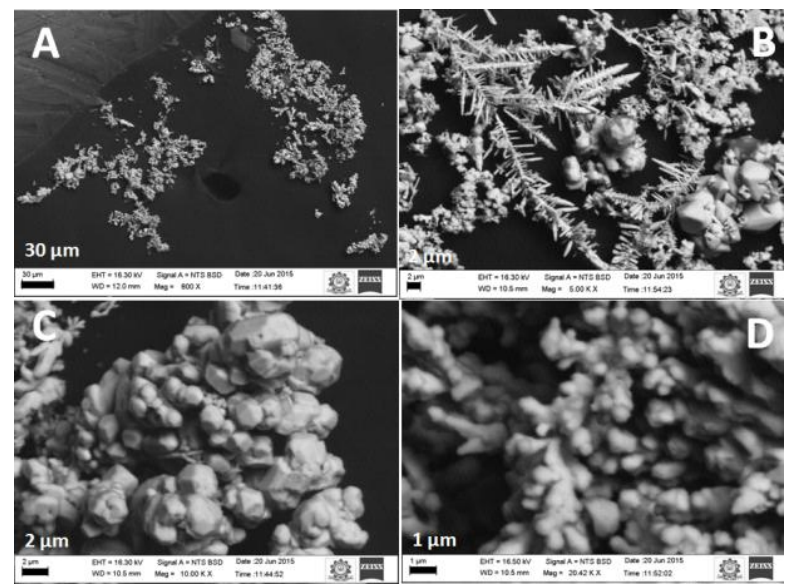

Fig. 3. SEM images of copper with DMF as capping agent

formation of thread like structures. This indicates that the change in hydrophobicity of the solvent helped to develop nano-rods instead of nanoparticles. Furthermore, the nano rods samples are not a single plain rod; but they are branched, which might have happened due to the regular attachment of atoms at nano level to get such a branched rods. To our knowledge no such arrangement of copper branched nano-rods has been reported using electrolysis until now. Some of surface modification of the nano-rods is under investigation to find useful applications of this material.

To confirm the role of hydrophobicity of the solvent in making the copper nanoparticles, we have examined with DMF in place of ethanediol and found very interesting shapes

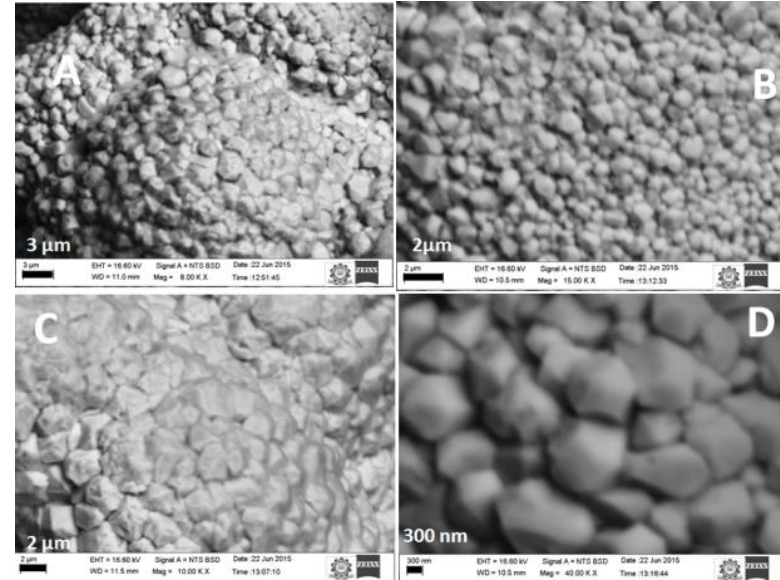

Fig. 4. SEM images of copper with milk as capping agent

of nanoparticles. As shown in Fig. 3. they formed less quantity of rod shaped nano materials and shifted more towards the spherical or hexagonal shaped nano materials. At the lower magnification (Fig. 3A), it showed uniformed size particles and at the next level (Fig 3B) of magnification, it displayed highly branched nanowires, with many irregular shaped nano crystals. At higher magnifications (Fig 3C and D), it appeared like a bunch of grape fruits. We presume that the addition of DMF to the copper solution, made the solution to hydrophobic and thus they started transforming from the branched rod shape to irregular spherical nanoparticles. This intrigued us to examine other hydrophobic molecules to control the shape of the copper nanoparticles under electrochemical conditions.

Table 1.

\begin{tabular}{|l|l|l|l|}
\hline $\begin{array}{l}\text { S. } \\
\text { No }\end{array}$ & $\begin{array}{l}\text { Name of } \\
\text { Additive }\end{array}$ & Nanostructure & Size (nm) \\
\hline 1. & Nil & $\begin{array}{l}\text { Spherical particles and } \\
\text { multidimensional } \\
\text { particles }\end{array}$ & $200-500$ \\
\hline 2 & Ethanediol & $\begin{array}{l}\text { Needle shape with less } \\
\text { crystalline }\end{array}$ & $100-200$ \\
\hline 3 & DMF & $\begin{array}{l}\text { Needle shape with more } \\
\text { crystalline shapes }\end{array}$ & $500-800$ \\
\hline 4 & Milk & $\begin{array}{l}\text { Multifaceted crystalline } \\
\text { shape }\end{array}$ & $200-300$ \\
\hline
\end{tabular}

To confirm this concept, we used milk as a protein source and examined the electrochemical deposition method with milk. For that purpose, we mixed milk ( $3 \mathrm{~mL}$ ) with copper sulfate $(5$ $\mathrm{g}, 100 \mathrm{~mL}$ water) and it formed a turbid solution, which was reduced using DC electricity to allow the deposition of copper nanoparticles. As expected, milk protein also lead to the formation of partially spherical nanoparticles in the range of 500 to $800 \mathrm{~nm}$ size with uniform distribution of particles (Fig. 4) As shown in the Fig. 4A, the particles were formed very uniformly with the milk and these particles are well capped with the milk protein as the surface of the particles are shiny and smooth surfaces.

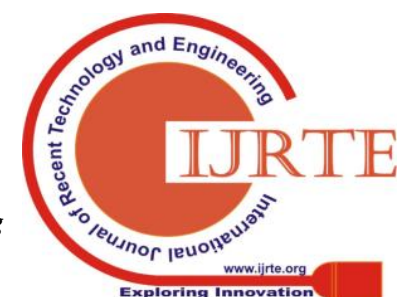




\section{CONCLUSION}

Overall, electrochemical method is a non-toxic way of preparing the nanoparticles, with different capping agents such as milk. Whenever we used the solvents such as ethanediol and DMF, copper nanopartilces tend to form the branched copper rods with a minor quantity of copper crystals due to the hydrophobic effect of the solvent (Table 1). Therefore, capping agent plays a major role in defining the shape and structure formation of the nanoparticles during the electrochemical deposition method. To our knowledge, this is the first report to study the shape selectivity of copper nanoparticles under hydrophobic environment, and that has been compared with copper nanoparticles with capping agent. Applications such as antibacterial studies and other nano-assembly of these nanowires are under investigation.

\section{ACKNOWLEDGMENT}

This work is financially supported by DST- SERB, India under Early Career Research Award (ECR/2015/000318). R. $P$ thanks to KARE for offering University PhD fellowship. G. U. thanks to the SERB for offering Project Assistant fellowship. Y. Jamuna and M. Aparna thanks to the KARE for offering summer internship programs

\section{REFERENCES}

1. D. Zhang, R. Wang, M. Wen, D. Weng, X. Cui, J. Sun, H. Li and Y. Lu, "Synthesis of Ultralong Copper Nanowires for High-Performance Transparent Electrodes" J. Am. Chem. Soc., vol. 134, July 2012, pp. $14283-14286$

2. Z. Liu, J. Xu, D. Chen and G. Shen, "Flexible electronics based on inorganic nanowires" Chem. Soc. Rev., vol. 44, Jan. 2015, pp. 161 -192 ,

3. Y. Liu, Z. Liu, N. Lu, E. Preiss, S. Poyraz, M. J. Kim and X. Zhang, "Facile synthesis of polypyrrole coated copper nanowires: a new concept to engineered core-shell structures" Chem. Commun., vol. 48 , Jan 2012, pp. $2621-2623$

4. S. Poyraz, Z. Liu, Y. Liu, N. Lu, M. J. Kim and X. Zhang, "One-step synthesis and characterization of poly(o-toluidine) nanofiber/metal nanoparticle composite networks as non-enzymatic glucose sensors" Sens. Actuators, B. , vol. 201, October 2014, pp. $65-74$,

5. Y. Wei, S. Chen, B. Kowalczyk, S. Huda, T. P. Gray and B. A. Grzybowski, "Synthesis of stable, low-dispersity copper nanoparticles and nanorods and their antifungal and catalytic properties" $J$. Phys. Chem. C, vol. 114, August 2010, 15612 -15616

6. Z. Liu, Y. Liu, L. Zhang, S. Poyraz, N. Lu, M. Kim, J. Smith,Wang, Y. Yu and X. Zhang, "Controlled synthesis of transition metal/conducting polymer nanocomposites" Nanotechnology, vol. 23, July 2012, pp. 335603.

7. Y-Q Liu, M. Zhang, F-X. Wang and G-B. Pan, "Facile microwave-assisted synthesis of uniform single-crystal copper nanowires with excellent electrical conductivity" $R S C A d v$., vol. 2, October 2012, pp. 11235-11237,

8. A. R. Rathmell, S. M. Bergin, Y. Hua, Z. Li and J. Benjamin, "The Growth Mechanism of Copper Nanowires and Their Properties in Flexible, Transparent Conducting Films" Wiley, Adv. Mater., vol. 22, August 2010, pp. .3558-3563.

9. W. Ye, J. Yan, Q. Ye, and F. Zhou "Template-Free and Direct Electrochemical Deposition of Hierarchical Dendritic Gold Microstructures: Growth and Their Multiple Applications" J. Phys. Chem. C, vol. 114, August. 2010, .pp. 15617-15624.

10. R. Prakash, G. Usha, L. Piramuthu and N. Selvapalam, "Facile Detection of Cucurbit[7]uril by Rhodamine B-decorated Nanoparticles" Chem. Lett., vol. 46, September. 2017, pp. $1300-$ 1303,

11. M. B. Gawande, A. Goswami, F-X Felpin, T. Asefa, X. Huang, R. Silva, X. Zou, R. Zboril, and R. S. Varma, "Cu and $\mathrm{Cu}-\mathrm{Based}$ Nanoparticles: Synthesis and Applications in Catalysis", Chem. Rev., vol. 116, March 2016, pp 3722-3811.
12. T. Theivasanthi and M. Alagar "Nano sized copper particles by electrolytic synthesis and characterizations", Int. J. Phys. Sci., vol. 6, August, 2011, pp. 3662-3671.

\section{AUTHORS PROFILE}

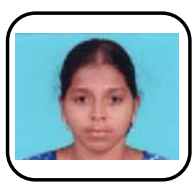

Govindaraj Usha. was born in Tirunelveli, Tamilnadu in 1991. She received her M.Phil degree from the Bharathiar university, Coimbatore, in 2015 and obtained her M. Sc. degree in 2013 at karunya University, Coimbatore. She has started her Ph. D. studies in 2016 under the supervision of Dr. N. Selvapalam at kalasalingam Academy of Research and Education, Krishnankoil, India. Her research interests are in the area of organic synthesis and supramolecular chemistry

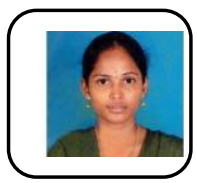

Jamuna Kannan born in Madurai,Tamilnadu in 1992. She received her M.Phil degree from the Madurai Kamaraj University in 2017. She obtained her M. Sc. degree in 2016 at Lady Doak College, Madurai. She joined Ph.D. in 2018 under the supervision of Dr. S. Sivakumar at Madurai Kamaraj University, Madurai. Her research interest is on the area of synthesis of Organic Materials, its material and biochemical application.

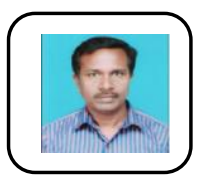

Dr. Narayanan Selvapalam received his M.S.and Ph.D. degrees from Mysore University and IIT Delhi, respectively. $\mathrm{He}$ is presently working as Associate Professor at the Kalasalingam Academy of Research and Education (Kalasalingam University) His research interests include supramolecular chemistry, glycoluril based polymers, Chemistry of cucurbiturils and cyclodextrins, organic synthesis and sensors.

Ramesh Prakash born in Karur,Tamilnadu in 1991. He received his M.Phil degree from the BharathidasanUniversity, Trichy, in 2015 and obtained his MSc degree in 2014 at St. Joseph's College, Trichy. He joined Ph.D. in 2015 under the supervision of Dr. N. Selvapalam at Kalasalingam Academy of Research and Education inVirudhunagar district. He is awarded a direct-Senior Research Fellowship from CSIR in 2018 to till date. His research interest is on the area of nanomaterials synthesis and supramolecular chemistry.

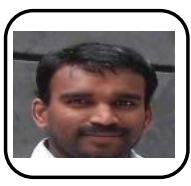

Dr. Lakshminarayanan Piramuthu was born in Kizhapuliyur, Tenkasi, India, in 1979. He studied Chemistry at Sri Paramakalyani College, Alwarkurichi, India. He obtained his Ph.D. degree in the area of Development of Receptors for Recognition of Halides and Water Clusters: Further Functionalization of Receptors with Fluorophoric Units from Indian Association for the Cultivation of Science IACS, Kolkata under the direction of Professor Pradyut Ghosh. His basic focus is, to study the biologically relevant anion recognition and sensing of the synthetic receptors, he has also contributed to other areas such as crystal engineering and organic synthesis. 